\title{
Elaboración de material multimedia para la asignatura “Las Provincias Romanas"
}

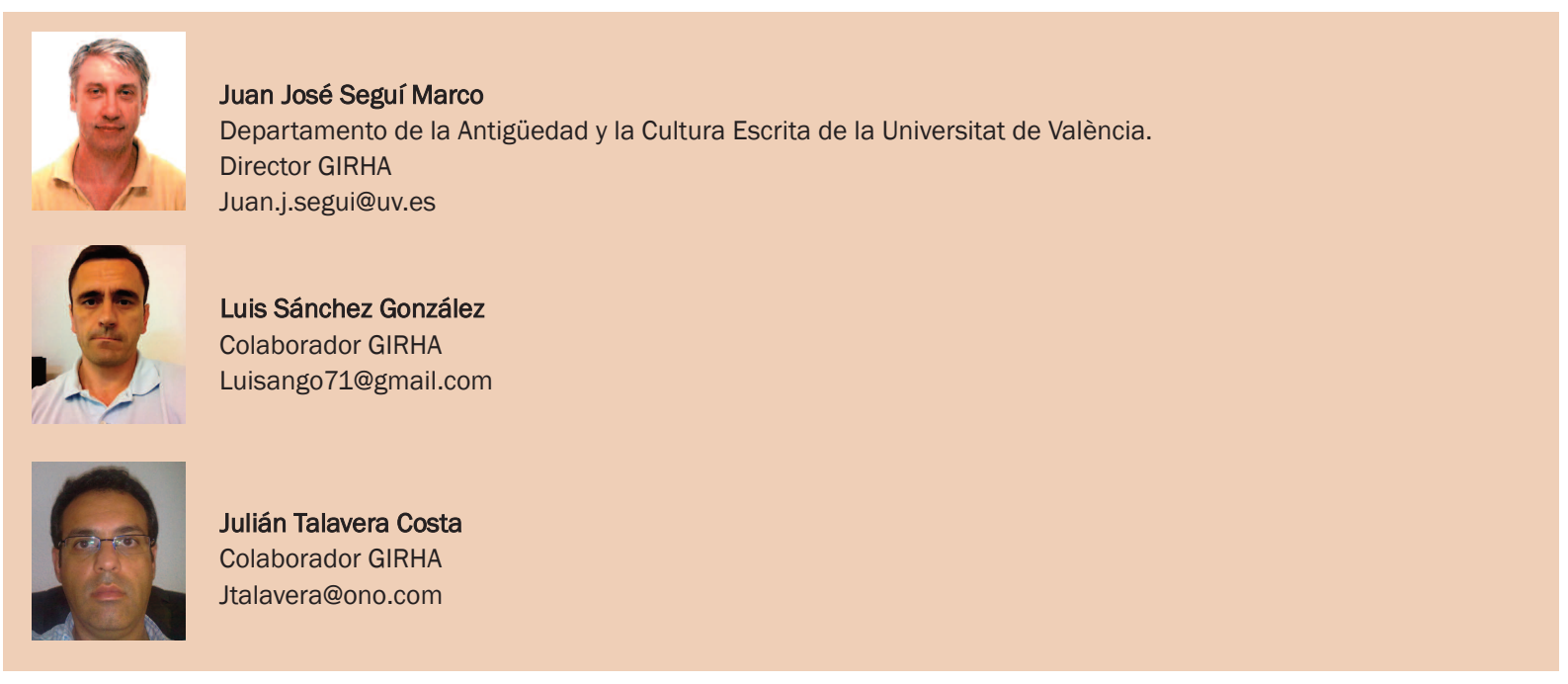

|Fecha presentación: 18/01/2011 | Aceptación: 05/04/2011 | Publicación: 21/06/2012

\section{Introducción}

Dentro de las ayudas a Proyectos de Innovación Educativa (subprograma Docent TIC) convocadas por el Vicerrectorado de Convergencia Europea y Calidad de la Universitat de València para el curso académico 2008-09, se presentó el proyecto titulado Elaboración de material multimedia para la asignatura "Las Provincias Romanas". Los motivos de la iniciativa estaban determinados por la urgente necesidad de crear material didáctico de apoyo a la tarea docente del profesor y al aprendizaje de los alumnos para la indicada asignatura, una optativa de $5^{\circ}$ curso, de 4,5 créditos, integrada en la Titulación de Historia de la Facultad de Geografía e Historia de la Universitat de València. Su elección como experiencia piloto que después podría extenderse a otras disciplinas del Área de Historia Antigua se basaba en que reunía una serie de características privilegiadas:

1. Impartición por un solo profesor, pero vinculado a otros colegas por afanes de renovación docente, lo que permitía aunar el control directo de la asignatura con el refuerzo que aportarían otros compañeros.

2. Presentaba un grado de matriculación muy elevado con un promedio de 90 alumnos- en el que figuraban estudiantes Erasmus de origen francés, italiano, alemán, belga y británico, así como de libre opción para otras carreras, como Derecho, Filología Clásica o Arte.
3. Continuidad de la asignatura en un máster en Historia de la Formación del Mundo Occidental, y con influencia directa sobre asignaturas troncales de grado, como Historia Antigua II.

4. Ausencia de manuales y materiales específicos que contribuía a complicar la dificultad del alumno para moverse en este campo de estudios, que se verían sensiblemente mejorados creando un acceso rápido e interactivo a través de una plataforma que garantizara su máximo aprovechamiento.

5. Gran cantidad de material acumulado y clasificado por el profesorado de la asignatura durante los años de docencia.

El proyecto se constituyó a partir del grupo GIRHA (Grupo de Innovación de Recursos en Historia Antigua), plataforma estable de recursos docentes del Área de Historia Antigua de la Universitat de València. El GIRHA cuenta desde el año 2003 con un espacio Web dedicado a la Historia Antigua (www.uv.es/girha) donde se puede encontrar todo tipo de información y recursos sobre esta especialidad. El interés que hasta el momento ha despertado esta página se evidencia en las numerosas consultas y descargas de materiales que ha recibido tanto a escala nacional como internacional, muy en especial, en el ámbito iberoamericano. El GIRHA cuenta con una amplia trayectoria en temas de 
apoyo a la docencia mediante la creación de recursos adaptados a las necesidades de alumnos y profesores. Entre ellos destaca un trabajo de recursos de Historia Antigua del País Valenciano, dentro del "Plan de aplicación de los TIC a los procesos educativos", titulado Materiales docentes de Historia Antigua del País Valenciano, y financiado por la Universitat de València. Esta experiencia, a través de la plataforma WebCT, prosiguió en 2002-03 mediante acceso on-line, con temario, apuntes, materiales gráficos y ejercicios de auto-evaluación.

Los siete integrantes y colaboradores del equipo de trabajo se constituyeron siguiendo las características disciplinares e interdepartamentales que regían la estructura organizativa del GIRHA: Áreas de Historia Antigua, Derecho Romano, Filología Clásica y equipo técnico de colaboradores.

\section{Metodología}

Se decidió adoptar la siguiente metodología de trabajo:

Fase I (septiembre-enero 2008): La vigencia de esta asignatura desde hace algunos años permitía contar con un fondo documental apreciable, si bien aún presentaba insuficiencias. Por consiguiente, esta fase se concentró en agregar nuevos materiales (textos, mapas, etc.), adecuados a los fines del proyecto. Para ello se revisaron bibliografías, fondos gráficos de museos e instituciones culturales, material en red, etc. La documentación recopilada se almacenó en una base de datos distribuida en carpetas temáticas y en archivos de texto, imagen y sonido.

Fase II (febrero-junio 2009): Se procedió a incorporar los materiales a un software interactivo. Aprovechando el periodo de docencia de la asignatura se experimentó con los alumnos aquellas partes que ya estaban elaboradas, atendiendo a sus sugerencias para mejorar los resultados.

Fase III (junio-septiembre 2009): Complementación de los materiales y ajuste a un formato de presentación definitiva que había de estar lista para el segundo cuatrimestre del curso 2009-2010 o, a lo sumo para el curso siguiente, bien entendido que el proceso de mejora debería ser constante.

\section{Resultados}

Los resultados han sido altamente satisfactorios y se han sustanciado en los siguientes logros:

1. Se han redactado 8 temas de los diferentes conjuntos provinciales presentados en formato pdf que cubren todo el diseño curricular de la materia:

1.1. Introducción: concepto de la materia y evolución historiográfica.

1.2. Italia.

1.3. Las provincias occidentales (Gallia, Hispania y Britannia).

1.4. África romana.

1.5. Las provincias renanas, danubianas y balcánicas.

1.6. Las provincias griegas. Asia Menor.

1.7. Egipto.

1.8. Las provincias orientales.

2. Confección de material y tutoriales para hacer el trabajo/s obligatorio/s de la asignatura:

2.1. Elaboración de 33 fichas provinciales, siguiendo una plantilla elaborada por el equipo de colaboradores donde se recogen los aspectos esenciales de cada una, tales como la geografía, los recursos naturales, la economía, los rasgos étnicos, etc.

2.2 Incorporado de planos y fotografías de 73 ciudades, siguiendo una presentación uniforme combinando texto histórico con material gráfico, y que conforman una unidad básica de información. Se ha empleado la siguiente metodología:

2.2.1. Apartado gráfico. Todas las ciudades tienen, al menos, 1 imagen, y un máximo de 5 , sumando todas ellas 250 imágenes. Todas las imágenes pueden ser guardadas por el alumno como material complementario de la asignatura.

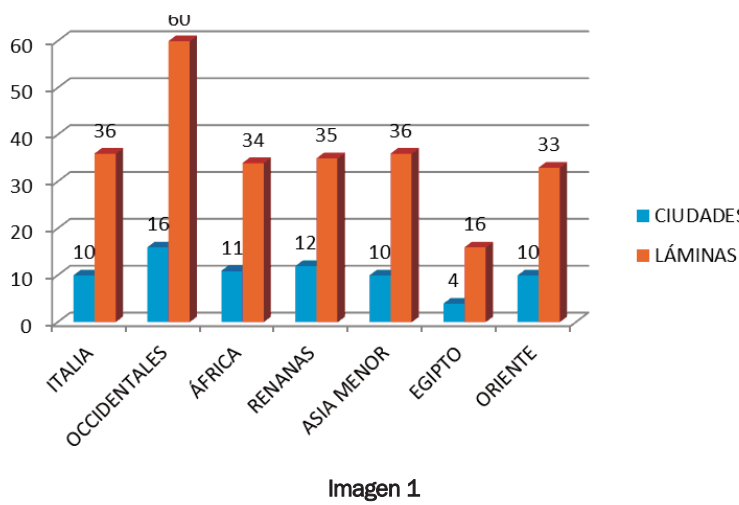

2.2.2. Obsérvese en el anterior gráfico los indicadores cuantitativos del material aportado: Cada imagen o cada grupo de dos imágenes como máximo, tiene un cuadro de texto explicativo, que se encuentra alojado en un fichero en formato pdf, que bien puede ser abierto de modo inmediato, bien se puede guardar para que el alumno lo emplee como material de la asignatura. Esa parte ha sido complementada mediante un contenido singularizado, centrado en un texto amplio, la Vida de Julio Agrícola de Tácito. Asimismo, se han agregado mapas provinciales para favorecer la ubicación espacial de los diversos contenidos, y tampoco ha faltado la inclusión de vídeos que pudieran ilustrar aspectos relevantes de la materia. Finalmente, se ofrece una pormenorizada bibliografía.

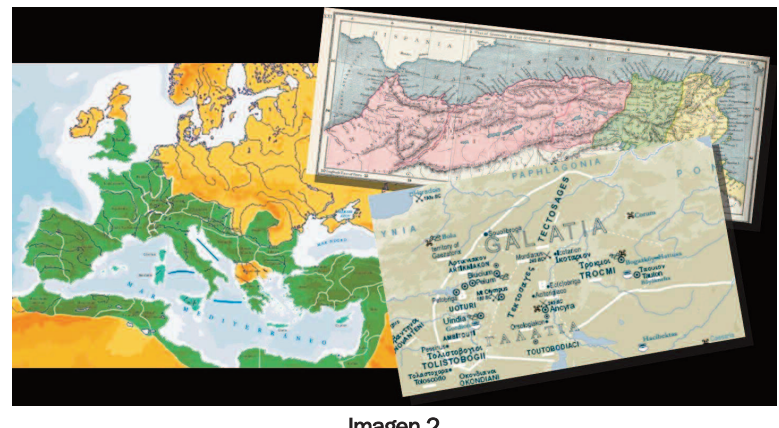

Imagen 2

3. Se han dispuesto diversos ítems de auto evaluación para los alumnos, pues dada la diversidad de contenidos y de la existencia de una prueba final de evaluación es conveniente ofrecerles un modelo que les permita experimentar su grado de conocimientos y el prototipo de examen. Como en la prueba final también se pondera la capacidad de desarrollo literario de preguntas de extensión y de resolución de supuestos prácticos se ha introducido un modelo de comentario de textos. 
La elaboración del material multimedia ha partido de la plataforma gratuita de Google, que permite crear páginas web y la inclusión de materiales auxiliares (sin necesidad de software previo) a modo de documentos que pueden ser consultados por el alumnado sin problemas, o descargados a su ordenador. Así entendemos que existen dos niveles de información básicos, por un lado el material más visual, esto es la página web tradicional, y por otro lado el más específico de cada tema, existentes en los documentos. La aplicación de Google permite, además, emplear otro tipo de instrumentos muy útiles desde el punto de vista docente como ejercicios de autoevaluación, calendarios de la asignatura, elaboración de estadísticas o cuentas de correo electrónico exclusivas del propio curso (Rivero, 2006). De esta forma, el profesor puede comunicarse con sus alumnos de manera más eficaz sin que interfiera en su correo institucional. El material final es un conjunto de páginas web, desarrolladas a modo de árbol jerárquico. Los materiales elaborados en este Proyecto pueden visualizarse en la página: https://www.Google.com/accounts/ServiceLogin? continue=http: /sites.Google.com/site/lasprovinciasro$\underline{\text { manas } / \& \text { service }=\text { jotspot\&passive }=\text { true\&ul }=1}$, accediendo mediante el usuario docentic.uv@gmail.com y una contraseña.

Estimación autocrítica de resultados:

1. Aspectos positivos:

1.1. Se ha dotado a la asignatura de una potente herramienta de trabajo, plenamente adaptada a las TIC. El soporte creado permite su adaptación a cualquier tipo de docencia: presencial, semi-presencial o no presencial.

1.2. Ha servido de incentivo para el grupo GIRHA, que puede ahora proyectar sus acciones sobre otras asignaturas sobre la base de una mayor experiencia.

2. Elementos mejorables:

2.1. Un punto a revisar de cara al futuro de la aplicación sería un cambio de plataforma. Depender de una herramienta perteneciente a una empresa privada (Google) es siempre un riesgo, que crea una peligrosa supeditación. Lo ideal es que la propia Universidad de Valencia genere una solución a este problema.

2.2.Mejora de diversos aspectos, en especial, la elaboración de mapas propios con la participación del alumnado, la ampliación y depuración de los textos, y el incremento del material filmado.

2.3.En suma, una mejora continua que se abordará en los cursos inmediatos.

Por todas estas razones y sobre todo por los argumentos mencionados anteriormente, intentamos impulsar, mantener y engrandecer el proyecto. La cantidad de materiales, así como la calidad de los mismos alojados en el entorno web, exceden con creces las necesidades y contenidos propios de la asignatura; incluso cabría la posibilidad de ser recoger otros enlaces a proyectos similares, como Arte Romano, Derecho Romano, Filología Clásica, etc.

\section{Bibliografía}

Alcock, SusanE., (Ed.), The Early Roman Empire in the East, Oxford, 1997.

Armas, Xoxé., «Didáctica de las Ciencias Sociales, Geografía e Historia», Diccionario Enciclopédico de Didáctica. Vol. I, pp. 161-16, Málaga, 2004.

Beltrán, Francisco.- Marco, Francisco., Atlas de Historia Antigua, Zaragoza, 1996.

Brown, Sally. - Glasner, Angela (Ed.)., Evaluar en la Universidad. Problemas y nuevos enfoques. Madrid: Narcea, 2007.

Cancik, Hubert. - Schneider, Helmuth. (Ed.), Brill's New Pauly. Encyclopaedia of the Ancient World. Antiquity, Leiden, 2002 ss.

De Miguel, Mario. (Coord.), «Metodologías de la enseñanza y aprendizaje para el desarrollo de competencias. Orientaciones para el profesorado universitario ante el espacio europeo de educación superior. Madrid, 2006.

Hammond, Nicholas Geoffrey Lempriere - Scullard, Howard Hayes. (Ed.), The Oxford Classical Dictionary, Londres, 1996.

Martin, Jean-Pierre , Les provinces romaines d'Europe centrale et occidental (31 av.-235 apr. J.C.), Paris, 1990.

Millar, Fergus, The Roman Near East, 31 B.C.-A.D. 337, Cambridge (Massachusetts), 1993.

Onrubia, Javier., «Aprender en entornos virtuales de enseñanza y aprendizaje: actividad conjunta, ayuda pedagógica y construcción del entendimiento». RED. Revista de Educación a Distancia. Año IV. Monográfico II, 2005. http://www.um.es/ead/red/M2/conferencia onrubia

Rivero, $\mathrm{M}^{\mathrm{a}}$ Pilar, «De derrota en derrota hasta la victoria final: experiencias con internet en didáctica de las ciencias sociales». I Jornadas de innovación docente, tecnologías de la información y la comunicación e investigación educativa en la Universidad de Zaragoza, celebradas en Zaragoza el 23 y 24 de noviembre de 2006. http://www.ub.es/histodidactica/

Sartre, Maurice, El Oriente romano, Madrid, 1994.

Talbert, Richard John Alexander (Ed.), Barrington. Atlas of the Greek and Roman World, Princeton-Oxford, 2000.

Varios, L'impero mediterraneo. I principi e il mondo II 2, en Storia di Roma, Turín, 1991.

Varios, «The Augustan Empire, 43 B.C.-A.D. 69», Vol X, ( $\left.2^{\mathrm{a}}\right)$, en The Cambridge Ancient History, Cambridge, 1996. 